\title{
IMPLEMENTATION OF STATISTICAL PROCESS CONTROL (SPC) FOR MANUFACTURING PERFORMANCE IMPROVEMENT
}

\author{
Farzana Sultana \\ School of Engineering and Computer Science \\ Independent University of Bangladesh, 58, Park Road, Baridhara, Dhaka 1212, Bangladesh \\ Nahid Islam Razive \\ Supply Chain Department \\ Nestle (Bangladesh) Ltd., Gulshan Tower, North Gulshan C/A, Dhaka - 1212, Bangladesh \\ Abdullahil Azeem* \\ Department of Industrial and Production Engineering, \\ Bangladesh University of Engineering and Technology, Dhaka - 1000, Bangladesh \\ *Corresponding email: azeem@ipe.buet.ac.bd
}

\begin{abstract}
This paper intends to combine the Hourly Data System (HDS) and Statistical Process Control (SPC) practices to improve manufacturing performances in manufacturing companies. The focus of this work is to find out the frequencies and time duration of machine breakdowns as well as the major causes of breakdowns affecting productivity. Total quality management (TQM) was introduced to improve continually the products or services to increase the customer satisfaction level. SPC is an important tool of TQM. Again HDS is the real time view of production floor of any manufacturing industry. In usual practice, SPC is used as quality control tool. However in this research SPC is used to increase total output identifying major loss times from various machine breakdowns using HDS. Successful implementation of the recommendations of this paper can significantly improve the manufacturing performance of a manufacturing environment.
\end{abstract}

Keywords: Total Quality management (TQM), Statistical Process Control (SPC), Hourly Data System (HDS)

\section{INTRODUCTION}

Total quality management (TQM) is a peoplefocused management system that aims at continual improvement in customer satisfaction. The most important tool of TQM is Statistical Process Control (SPC). It helps us monitoring a process continuously. The purpose of control charting is to indicate when the process is functioning as intended and when is not. Some appropriate corrective measures need to be taken whenever necessary. In a manufacturing environment, the SPC tool is used for continuous improvement of the production volume as well as quality which leads to achieve manufacturing excellence. The bottom line of any company is to make profit by achieving the customers' satisfaction. This can be achieved by proper implementation of the SPC tools. SPC can be used as quality control tool or it can contribute to increase the total volume of production. By this tool, the production manager can easily identify the causes responsible for poor product quality, machine breakdowns and also huge wastage.
Shop floor control is now-a-days a major concern of any manufacturing industry. The key to this shop floor control is Hourly Data System (HDS). HDS is the real time view of production floor of any manufacturing company. Usually the operators of the machines give input of the produced volume every hour. These hourly data is a reagent for the improvement of total productivity and to upgrade the production trend. It also provides the basic data for quality control (QC) analysis and Preventive Maintenance (PM). TQM is a prominent example of fundamental organizational change that many business leaders are introducing to their firms. Although hundreds of articles for practitioners have discussed specifics of TQM, and most experts agree that properly implemented quality systems improve organizational performance ${ }^{1}$, several surveys ${ }^{2}$ reveal disturbing statistics. A survey of 500 US executives showed that only about 30 per cent believed that their TQM programs made a competitive difference. Brown et al. ${ }^{3}$ cite information indicating that 50 to 75 per cent of all organizations implementing TQM drop their 
initiatives within the first two years. Statistical process control (SPC) techniques, in particular the control chart, have been widely used in the manufacturing industry ${ }^{4-5}$. Usually, control charts are implemented for the purpose of process monitoring.

Statistical process control (SPC) has become one of the most popular and widespread organizational interventions in the name of quality improvement ${ }^{6-7}$. SPC's industrial prominence can be explained, in part, by the quality and costs benefits that have been ascribed in literature to this quality improvement intervention ${ }^{8-9}$. This literature, however, is primarily anecdotal in nature, with an over-reliance on case studies ${ }^{10}$. As a result, despite numerous claims of SPC's quality and costs benefits, a scientific body of knowledge to justify and rationalize these benefits in the literature has not emerged.

Although SPC is being used widely in different manufacturing companies in Bangladesh; so far there is no study to relate Hourly Data System (HDS) and Statistical Process Control SPC to find out the frequencies and time duration of machine breakdowns as well as loss time affecting productivity. This paper intends to investigate the total quality management practice and breakdown record management practice in the context of a cigarette manufacturer and also to assess the contribution of these practices to find out major breakdown reasons according to their frequencies and breakdown time.

\section{METHODOLOGY}

The volume of cigarette packing department (CPD) has been taken for analyzing the performance of the machines. The major difference between brands lies in tobacco mixture and they have same packing and making process. As a result, each of the modules is capable of making cigarettes of various brands. So daily production volume is recorded both machine wise and brand wise. These records are then considered as the basis of quality analysis.

Six months CPD data has been taken for SPC analysis. These data are then plotted in Minitab, which is a Statistical Software for production trend analysis. Root causes of failure for production data which is out of control limit are then looked for from HDS, Maintenance Schedule, Communication Log Book, and Electrical Log Book and then the findings have been analyzed. After it recommendations are given based on findings. The study is done in a cigarette manufacturing company and the sequence of the study is given in the following flow chart (Fig. 1).

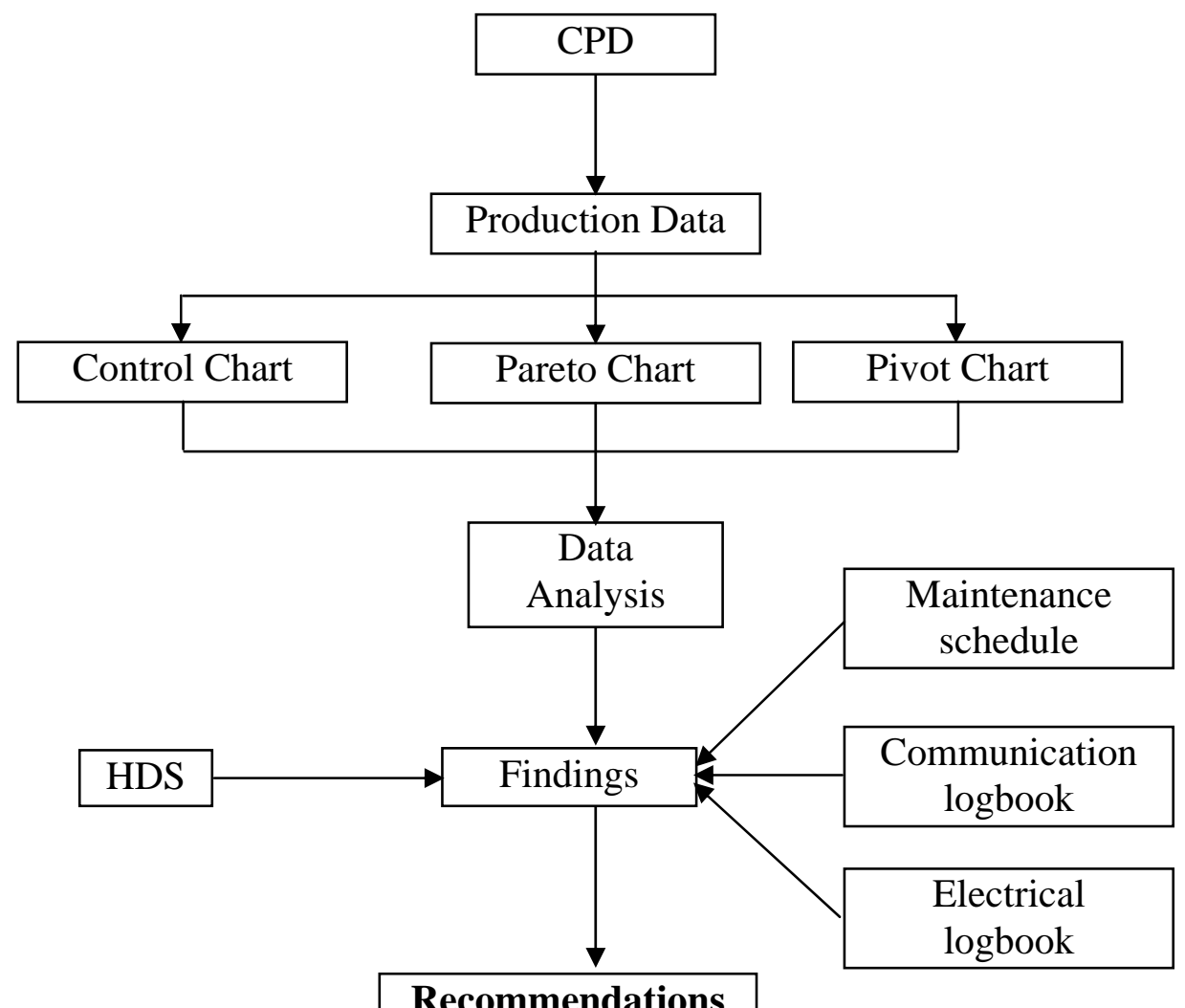

Figure 1. Flowchart of complete procedure 


\section{PRODUCTION DATA ANALYSIS}

\section{Determining Target Mean and Target SD}

For plotting the CPD data in control charts, the historical or target mean and standard deviation need to be determined first. The target mean should be a higher and achievable volume whereas the Standard Deviation (SD) should be as less as possible. But in real case, it is not rational to select historical mean and SD from two different months for plotting control chart. So a desirable combination of high and achievable mean and relatively smaller SD is chosen from same month from the available mean and SD. Table 1 shows the calculation of target Mean and SD for one particular machine.

After setting the target mean and standard deviation for production data, variable chart is plotted for CPD volume as a measurable unit. Statistical software Minitab is used to plot individual value and moving range type (I/MR) variable chart for produced volume in mentioned machine. Standard tests for control charts have been performed and upper control limit (UCL) and lower control limit (LCL) are calculated taking the target mean and standard deviation into consideration (Fig. 2).

Table 1. Production data of machine 1 (million packs)

\begin{tabular}{|c|c|c|c|c|}
\hline Month & Mean & SD & $\begin{array}{c}\text { Target } \\
\text { (Max) } \\
\text { Mean }\end{array}$ & $\begin{array}{c}\text { Target } \\
\text { (Min) SD }\end{array}$ \\
\hline 1 & 5.839 & 1.426 & \multirow{2}{*}{6.419} & 0.929 \\
\cline { 1 - 3 } 2 & 6.138 & 1.576 & & \\
\hline 3 & 6.419 & 0.929 & & \\
\cline { 1 - 2 } 4 & 5.578 & 1.508 & & \\
\hline 5 & 5.832 & 1.065 & & \\
\hline 6 & 6.351 & 1.092 & & \\
\hline
\end{tabular}

In the same manner, production data of another machine have been considered to choose a desirable combination of high and achievable mean and relatively smaller SD from same month from the available mean and SD. Table 2 shows the calculation of target Mean and SD for the second machine.

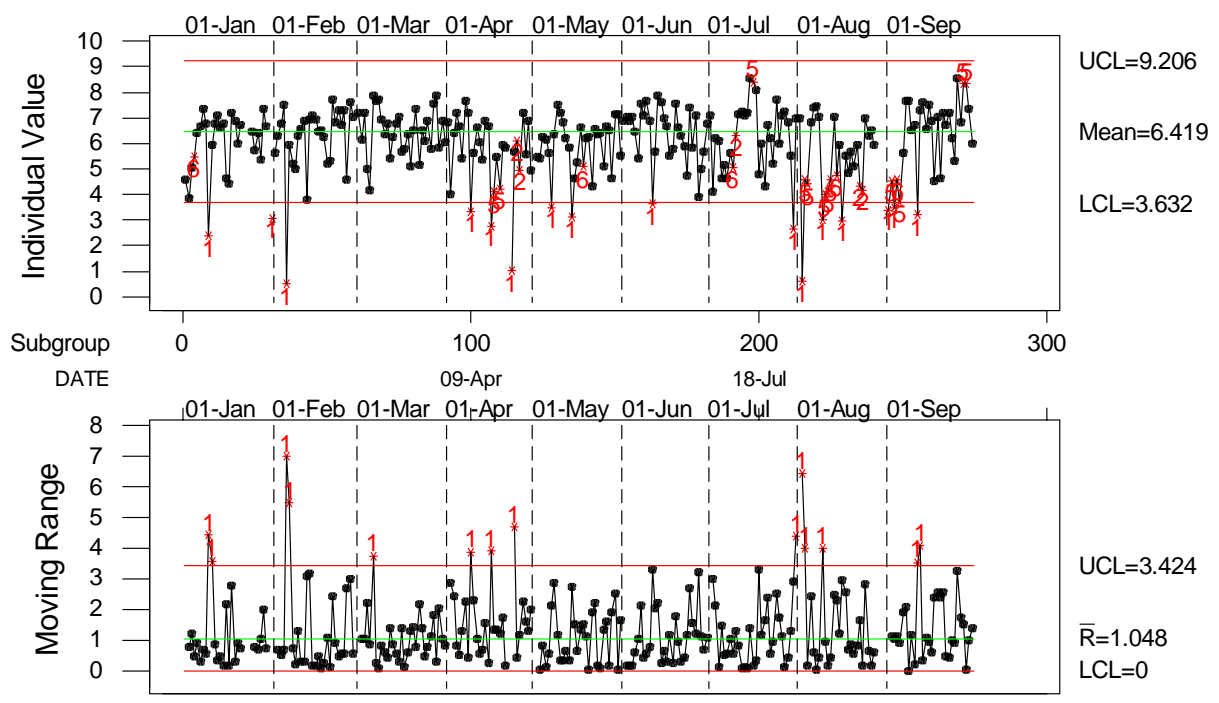

Figure 2. Control chart for CPD data (machine 1)

Table 2. Production data machine 2

(in million packs)

In the same manner, production data of another machine have been considered to choose a desirable combination of high and achievable mean and relatively smaller SD from same month from the available mean and SD. Table 2 shows the calculation of target Mean and SD for the second machine.

\begin{tabular}{|c|c|c|c|c|}
\hline Month & Mean & SD & $\begin{array}{c}\text { Target (Max) } \\
\text { Mean }\end{array}$ & $\begin{array}{c}\text { Target } \\
\text { (Min) SD }\end{array}$ \\
\hline 1 & 1.747 & 0.545 & & \\
\cline { 1 - 2 } 2 & 1.856 & 0.661 & \multirow{2}{*}{1.856} & \multirow{2}{*}{0.661} \\
\cline { 1 - 2 } 3 & 2.055 & 0.696 & & \\
\cline { 1 - 2 } 4 & 1.278 & 0.634 & & \\
\hline 5 & 1.124 & 0.597 & & \\
\hline 6 & 1.309 & 0.543 & & \\
\hline
\end{tabular}




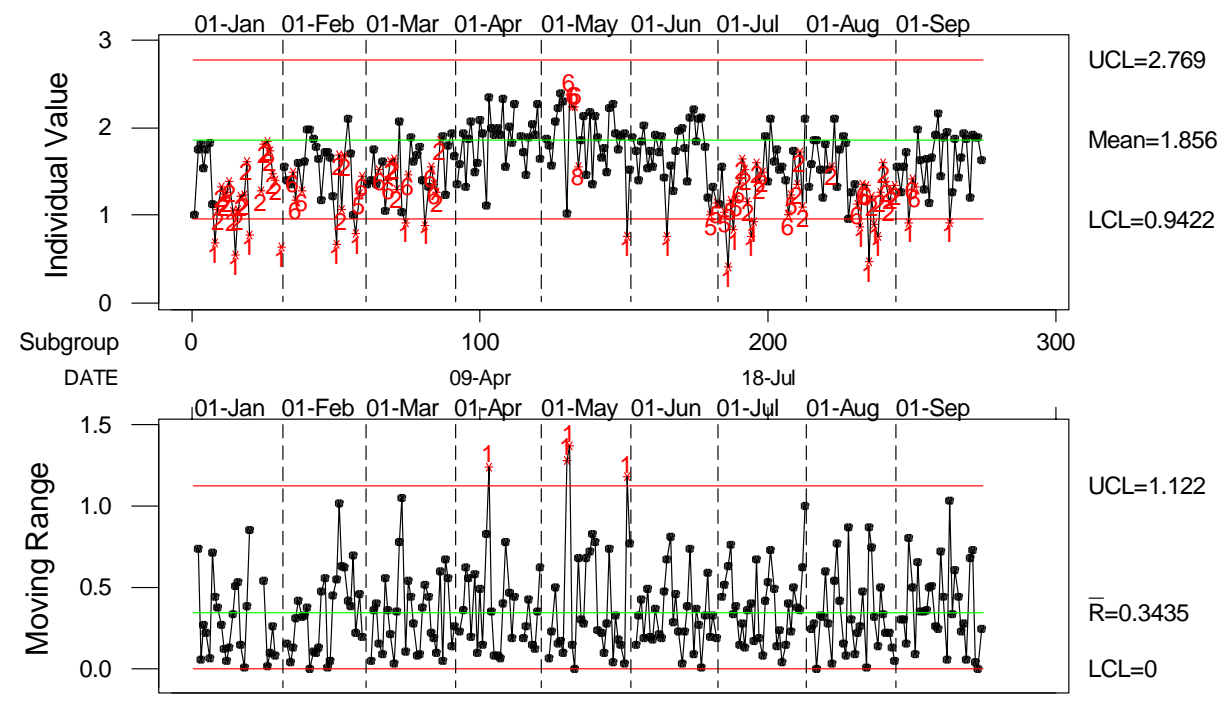

Figure 3. Control chart for CPD data (machine 2)

After setting the target mean and standard deviation for production data of the second machine, individual value and moving range type (I/MR) variable chart have been plotted for produced volume of the second machine. Standard tests for control charts have been performed and upper control limit (UCL) and lower control limit (LCL) are calculated taking the target mean and standard deviation into consideration (Fig. 3).

\section{LOSS TIME DATA ANALYSIS}

\section{Pareto Chart for Break-Down Time}

According to the rules of SPC chart, all the out of specification points have been detected. Each point on the control chart represents the total production volume of a particular day. The defects responsible for each individual out of spec data have been traced from HDS and the root causes of those defects are then analyzed. Based on this analysis, a pareto chart has been generated to identify the 'vital few' problems from the 'trivial many'.

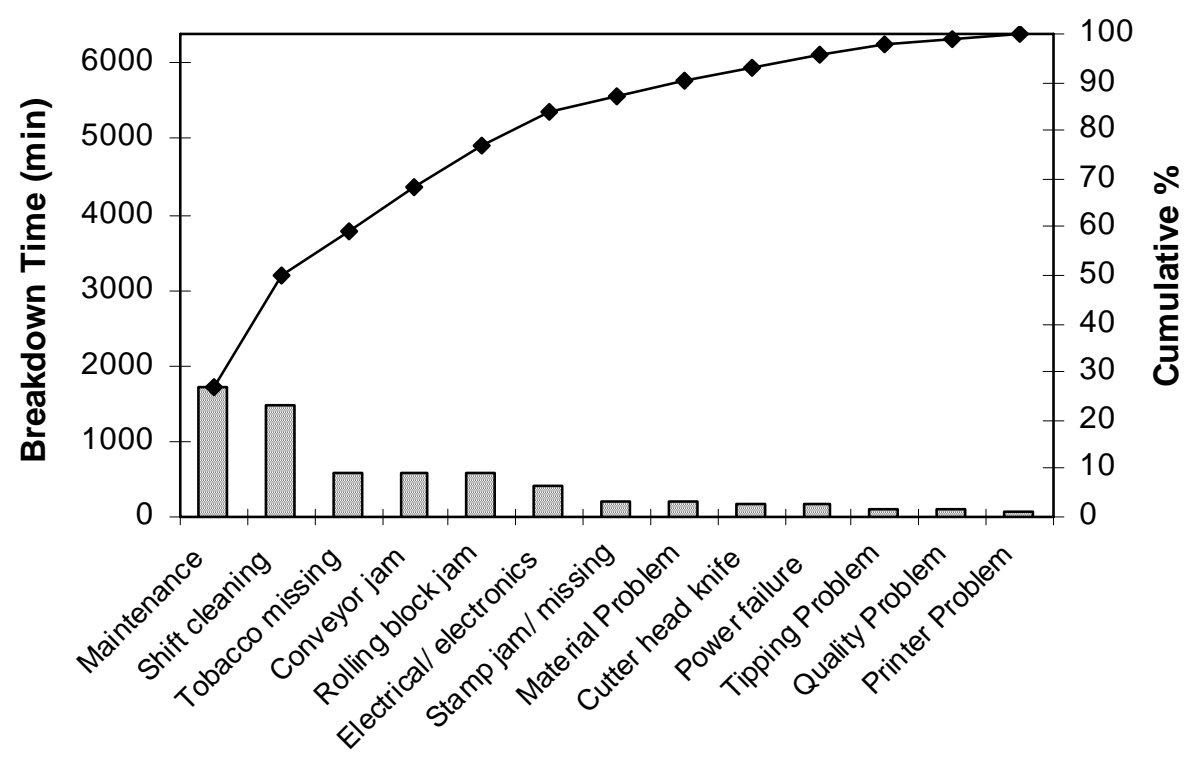

Loss Time Factors

Figure 4. Pareto chart for machine 1 breakdown 
As maintenance and shift cleaning is a desired part of performance improvement, rest of the causes that result in production loss need to focus on priority basis. A short $/ \mathrm{mid} /$ long term plan is to be designed to prevent or minimize those breakdowns. The pareto chart of all the factors that contributes in production disruption is depicted in Fig. 4.
Figure 5 shows another pareto chart for the second machine in consideration. This machine shows different breakdown data compared to the first one. Electrical/electronic failure is the most significant breakdown for this machine whereas tobacco missing problem is the second largest.

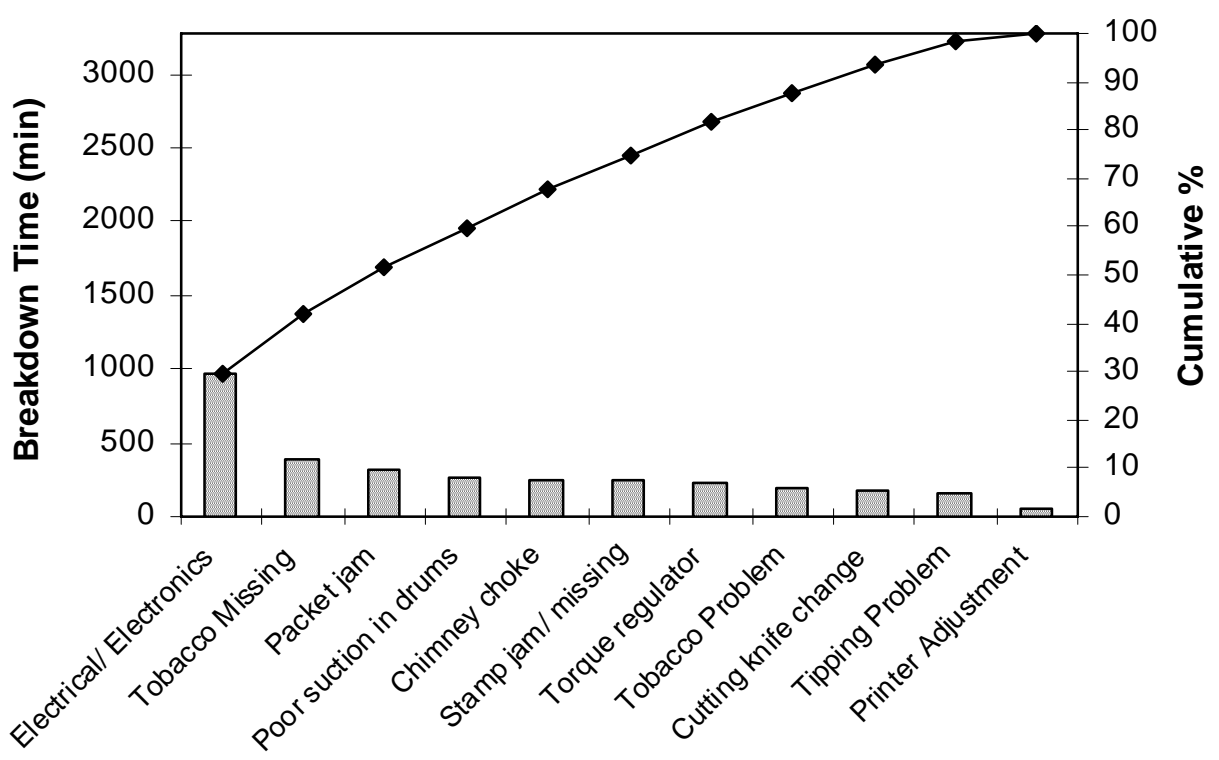

Loss Time Factors

Figure 5. Pareto chart for machine 2 breakdown

\section{Alert Signal before Major Breakdowns}

The best approach to address any breakdown is the preventive measure. Preventive maintenance is a scheduled maintenance program that prevents the machineries and equipments from unwanted breakdown in between production process. However, non-scheduled preventive maintenance is also important for any signal of probable breakdown in the coming operation time, so that one can take proper measures and can save a huge amount of money avoiding the consequent breakdown or stoppage time. Table 3 represents the weekly breakdown data from different problems for a single machine. From the first week data, it can be seen that the Conveyor jam is the leading cause for breakdown and Tobacco missing in prefeeder is the least. In second week data, Conveyor jam is still leading the breakdown list where as the Tobacco missing in pre-feeder problem moves up to fifth position posing a possible threat to the machine.
Table 3. Weekly breakdown data of machine 1

\begin{tabular}{|c|c|c|c|c|}
\hline $\begin{array}{c}\text { Loss time } \\
\text { factors }\end{array}$ & $\begin{array}{c}\text { Week 1 } \\
\text { (min) }\end{array}$ & $\begin{array}{c}\text { Week 2 } \\
\text { (min) }\end{array}$ & $\begin{array}{c}\text { Week 3 } \\
\text { (min) }\end{array}$ & $\begin{array}{c}\text { Week 4 } \\
\text { (min) }\end{array}$ \\
\hline $\begin{array}{c}\text { Conveyor } \\
\text { jam }\end{array}$ & 210 & 250 & 115 & 0 \\
\hline $\begin{array}{c}\text { Rolling } \\
\text { block jam }\end{array}$ & 165 & 150 & 175 & 85 \\
\hline $\begin{array}{c}\text { Cutter head } \\
\text { knife }\end{array}$ & 150 & 30 & 0 & 0 \\
\hline $\begin{array}{c}\text { Electrical/ } \\
\text { electronics }\end{array}$ & 120 & 120 & 90 & 90 \\
\hline $\begin{array}{c}\text { Stamp jam/ } \\
\text { missing }\end{array}$ & 60 & 105 & 55 & 0 \\
\hline $\begin{array}{c}\text { Printer } \\
\text { Problem }\end{array}$ & 55 & 0 & 0 & 0 \\
\hline $\begin{array}{c}\text { Tobacco } \\
\text { missing }\end{array}$ & 45 & 85 & 145 & 310 \\
\hline $\begin{array}{c}\text { Material } \\
\text { Problem }\end{array}$ & 0 & 30 & 180 & 0 \\
\hline $\begin{array}{c}\text { Tipping } \\
\text { Problem }\end{array}$ & 0 & 30 & 90 & 0 \\
\hline $\begin{array}{c}\text { Quality } \\
\text { Problem }\end{array}$ & 0 & 20 & 30 & 45 \\
\hline
\end{tabular}

J oumal of Mec hanical Engineening, Vol. ME 40, No. 1, J une 2009

Transaction of the Mech. Eng. Div., The Institution of Engineers, Bangladesh 
In the third week, breakdown due to material problem became the leading problem whereas the Tobacco missing in pre-feeder became third, keeping as well as increasing the machine threat. For the fourth week, this tobacco missing in prefeeder jumped to the top position and had the most adverse effect on machine breakdown time. Trend monitoring of these kinds of defects is therefore a prime concern to improve the overall condition of the machine as well as production. Quality problem, although not severe, is another potential defect that shows a negative trend and need to be rectified without further advancement. Any listed or unlisted defect can show this type of trend and should be prioritized according to their importance. Figure 6 shows the trend of Tobacco missing and Quality problem in four consecutive weeks.

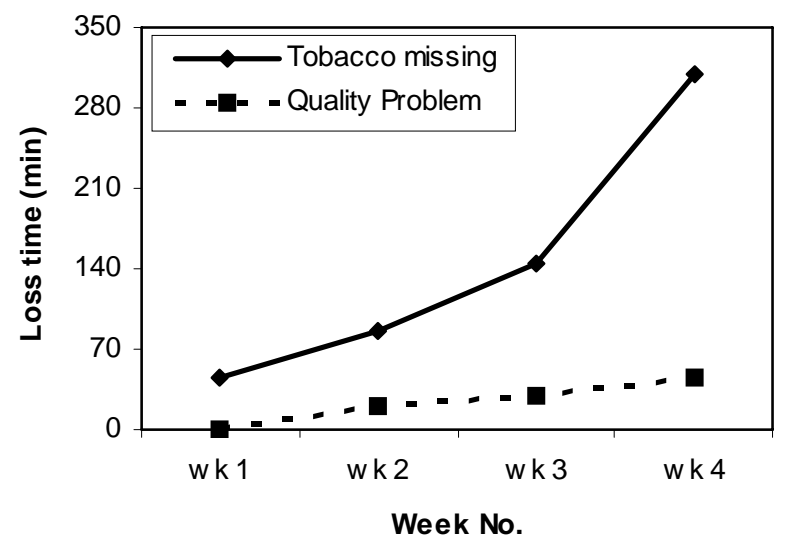

Figure 6. Trend for two significant defects during production (machine 1)

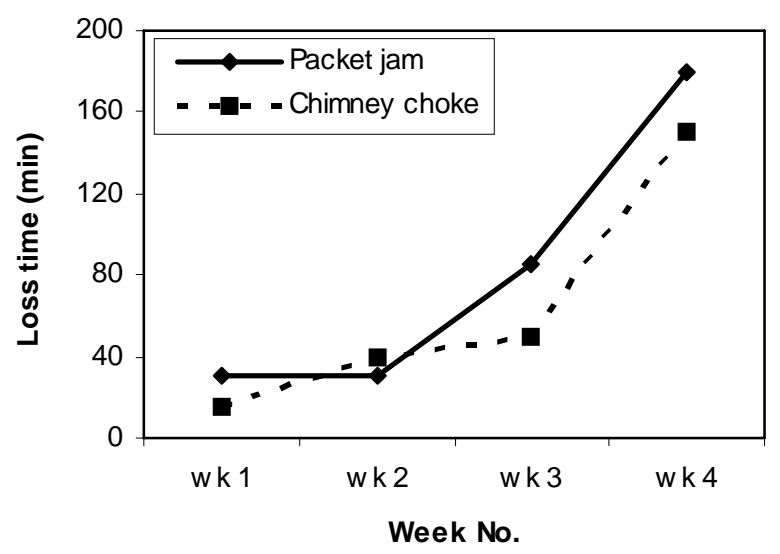

Figure 7. Trend for two significant defects during production (machine 2)

Breakdown trend for the second machine is shown in Table 4. Here the electrical/electronic failure contributes the most loss time in production. However, the trend of loss time due to this problem is not that much concerning. Rather, the trend of the loss time from packet jam shows that this failure is being increased at an alarming rate that needs to be taken care of. Another alarming signal is from chimney choke that costs the valuable production time. Figure 7 depicts the trend lines of these two alarming defects.

Table 4. Weekly breakdown data of machine 2

\begin{tabular}{|c|c|c|c|c|}
\hline $\begin{array}{c}\text { Loss time } \\
\text { factors }\end{array}$ & $\begin{array}{c}\text { Week 1 } \\
\text { (min) }\end{array}$ & $\begin{array}{c}\text { Week 2 } \\
\text { (min) }\end{array}$ & $\begin{array}{c}\text { Week 3 } \\
\text { (min) }\end{array}$ & $\begin{array}{c}\text { Week 4 } \\
\text { (min) }\end{array}$ \\
\hline $\begin{array}{c}\text { Tobacco } \\
\text { Missing }\end{array}$ & 250 & 50 & 40 & 50 \\
\hline $\begin{array}{c}\text { Tobacco } \\
\text { Problem }\end{array}$ & 160 & 25 & 0 & 15 \\
\hline $\begin{array}{c}\text { Electrical/ } \\
\text { Electronics }\end{array}$ & 125 & 640 & 105 & 105 \\
\hline $\begin{array}{c}\text { Stamp jam/ } \\
\text { missing }\end{array}$ & 125 & 40 & 40 & 35 \\
\hline $\begin{array}{c}\text { Poor suction } \\
\text { in drums }\end{array}$ & 50 & 140 & 60 & 15 \\
\hline $\begin{array}{c}\text { Tipping } \\
\text { Problem }\end{array}$ & 50 & 30 & 55 & 25 \\
\hline $\begin{array}{c}\text { Torque } \\
\text { regulator }\end{array}$ & 40 & 60 & 95 & 30 \\
\hline Packet jam & 30 & 30 & 85 & 180 \\
\hline $\begin{array}{c}\text { Chimney } \\
\text { choke }\end{array}$ & 15 & 40 & 50 & 150 \\
\hline $\begin{array}{c}\text { Printer } \\
\text { Adjustment }\end{array}$ & 0 & 0 & 60 & 0 \\
\hline
\end{tabular}

\section{ECONOMIC ANALYSIS}

\section{Loss Incurred from Machine Breakdown}

A huge loss can be incurred due to machine breakdown. If the capacity of a cigarette-making machine is 8,500 cigarettes per minute, then the capacity of a cigarette-making machine per hour is 510,000 cigarettes $(8,500 * 60)$. So if a machine does not work for one hour then there will be a loss of 510,000 cigarettes. If the average revenue per cigarette is $1.53 \mathrm{BDT}$ then total loss incurred for one hour machine breakdown will be 780,300 BDT.

\section{Loss Incurred from Non-conforming Product}

Non-conforming cigarettes are usually produced due to different quality problems like conveyor jam, tobacco missing, and stamp jam/missing etc. A huge loss also incurred due to non-conforming cigarettes production. If the capacity of a cigarette-making machine per hour is 510,000 cigarettes $(8,500 * 60)$ and total cost of goods sold is 0.354 BDT per cigarette (raw material cost @0.30 BDT/cig, salaries \& wages @0.04 BDT/cig, utilities cost @ 0.004 BDT/cig, Repair \& Maintenance cost @ 0.01 BDT/cig), then total loss will be $180,540(510,000 * 0.354)$ BDT per hour. As a result, total loss from nonconforming products will be 960,840 BDT. 
From the above interpretation it is clear that breakdown can cause a huge cost for a factory. If a machine does not work for one hour, the revenue loss is 780,300 BDT. And if a machine produces non-conforming cigarettes for one hour due to any quality problem, the loss is about 960,840 BDT. This loss will ultimately affect the total profit of any company. So in today's competitive manufacturing, this is of outmost importance to reduce total breakdown time as well as nonconforming products by continuous monitoring of machine breakdowns.

\section{CONCLUSIONS}

A detailed analysis has been done to find out the frequencies and time duration of cigarette making machine breakdowns as well as the major causes of those breakdowns. The obtained result shows that any breakdown can cause a huge cost and the best approach to address any breakdown is the preventive measure. The economic analysis has clearly affirmed the fact that any preventive measure assuming the breakdown patterns can help a lot in terms of revenue generation. If one can get any signal of probable breakdown in the coming operation time, he/she can take the preventive actions and can save a huge amount of money avoiding the consequent breakdown or stoppage time. This only can be done by analyzing the recent and past breakdowns and the causes of those breakdowns.

Moreover some production managers have the tendency to give concentration only on daily activities and solving of the breakdown causes. But this is not the right way to minimize the causes of breakdowns. More efficient technique is to focus on those specific issues that can affect a company in the long run. Long term corrective/ preventive actions are also needed to minimize or reduce these issues. Although SPC is primarily used as a quality control tool, it can also be used to improve the manufacturing performance of a factory.

\section{REFERENCES}

1. Garvin, D. A., 1987, "Competing on the eight dimensions of quality", Harvard Business Review, pp. 101-109.

2. Eskildson, L., 1994, "Improving the odds of TQM's success", Quality Progress, pp. 89-100.

3. Brown, M., Hitchcock, D. and Willard, M., 1994, "Why TQM Fails and What to Do about It”, Irwin Professional, New York, NY..

4. Krumwiede, D. and Sheu, C., 1996, "Implementing SPC in a small organization: a TQM approach", Integrated Manufacturing Systems, Vol. 7(1), pp. 45-51.

5. Rucinski, D. W., 1991, "SPC - more than quality control", Quality, Vol. 30, pp. 43-45.

6. Lascelles, D. M. and Dale, B. G., 1988, "A study of the quality management methods employed by U.K. automotive suppliers", Quality and Reliability Engineering International, Vol. 4 (3), pp. 301-309.

7. Modarress, B. and Ansari, A., 1989, "Quality control techniques in US firms: a survey", Production and Inventory Management Journal, Vol. 30 (2), pp. 58-62.

8. Bounds, G. M., 1988, Success in implementing statistical process control as a function of contextual variables in 20 manufacturing organizations, $\mathrm{PhD}$ dissertation, University of Tennessee at Knoxville, TN.

9. Dondero, C., 1991, "SPC hits the road", Quality Progress, Vol. 24 (1), pp. 43-44.

10. Gordon, M. E., Philpot, J. W., Bounds, G. M. and Long, W. S., 1994, "Factors associated with the success of the implementation of statistical process control", Journal of High Technology Management Research, Vol. 5 (1), pp. 101-21. 